\title{
PERANAN LEMBAGA PENDIDIKAN MA'ARIF NADHLATUL ULAMA DALAM PENYEBARAN PENDIDIKAN ISLAM DI INDONESIA
}

\author{
Maulana Ridwan \\ Madrasah Aliyah Pondok Pesantren Al-Falakiyah Bogor \\ E-mail: maulanaridwanbogor93@gmail.com
}

\begin{abstract}
Abstrak
Pendidikan Islam adalah ikhtiar sadar untuk memberdayakan umat Islam dalam kerangka pengembangan peradaban Islam. Setiap muslim, utamanya para pemikir dan pakar pendidikan Islam harus merasa terpanggil untuk mengembangkan dan memajukan pendidikan Islam. Pendidikan Islam yang diharapkan adalah pendidikan yang berorientasi pada kebutuhan nyata masyarakat Islam saat ini dan saat mendatang dengan tetap berpijak pada pendidikan Islam masa kejayaan Islam. ${ }^{1}$ Tujuan dari penelitian ini adalah: untuk mengetahui peranan Lembaga Ma'arif Nahdlatul Ulama dalam menjaga eksistensi pendidikan Islam yang moderat, juga peranannya dalam mengaktualisasikan pendidikan Islam di zaman yang terus berkembang. Bentuk penelitian yang digunakan adalah penelitian kualitatif deskriptif. Teknik yang digunakan untuk melakukan pengumpulan data dalam peneleitian ini adalah melalui Pengamatan, Wawancara, Observasi dan Triangulasi. Hasil penelitian bahwa Lembaga Pendidikan Ma'arif NU mampu menciptakan suasana pendidikan yang tidak hanya mengemban misi keagamaan saja, melainkan mampu mengembangkan Sumber Daya Manusia yang potensial sesuai bakat dan keahliannya.
\end{abstract}

Kata Kunci: LP Ma’arif NU, penyebaran, pendidikan Islam di Indonesia

\section{Pendahuluan}

Pendidikan islam telah tumbuh seiring dengan kelahiran dan pertumbuhan penyebaran islam itu sendiri, yang sangat terkait dengan proses Islamisasi. Ini menunjukan betapa pentingnya sebuah pendidikan dalam sejarah perjalanan manusia, khususnya umat islam. Sehingga setiap generasi dengan kemampuannya sendiri mengembangkan dan melanjutkan apa yang telah dicapai oleh generasi sebelumnya.

Jika diulas kembali pada sumber-sumber sejarah Islam sejak zaman klasik, pertengahan, hingga zaman modern. Yakni sejak zaman Rasulullah SAW, Khulafaur Rasyidin, Bani Umayah, Bani Abbas, Dinasti-dinasti kecil, kesultanan Turki Utsmani, Kesultanan Mughal di India, dan Kesultanan Syafawi di persia, yang belangsung sejak abad ke-7 M s.d. 18 M.

Pada zaman tersebut, sejarah mencatat bahwa dunia Islam tampil sebagai pencetus, pelopor, pemimpin, pemandu, dan pusat peradaban dunia. Pada masa itu,

${ }^{1}$ Rohani HM, Ahmad, "Pendidikan Islam, menuju generasi khairu ummah", Portal Garuda, Vol 47, No 118. 2009

Fikrah: Journal of Islamic Education, P-ISSN : 2599-1671, E-ISSN : 2599-168X 
umat Islam bukan hanya menguasai ilmu agama Islam dengan berbagai cabangnya (tafsir, hadits, fikih, kalam, filsafat islam, tasawuf, dan sejarah kebudayaan Islam), juga ilmu umum dengan berbagai cabangnya (fisika, matematika, astronomi, geometri, kedokteran, farmasi, sosial, ekonomi, politik, dan lain-lain).

Melalui berbagai catatan sejarah, dapat dijumpai bahwa terjadinya kemajuan Islam tersebut karena didukung oleh kemajuan dalam bidang pendidikan dalam arti luas, yaitu pendidikan yang dilakukan oleh lembaga-lembaga baik yang dibangun oleh pemerintah, masyarakat, atau perorangan. ${ }^{2}$ Atas kesadaran serta kepeduliaan terhadap pendidikan itulah, peradaban Islam mencapai puncak kejayaan.

Dalam sejarahnya, Islam di Indonesia sendiri memiliki relasi yang cukup baik dengan tradisi lokal. Interaksi dinamis antara Islam dan tradisi lokal membentuk Islam yang khas. ${ }^{3}$ Dalam hal pendidikan misalnya, para ulama banyak mendirikan lembagalembaga pendidikan dengan cara mengambil-alih lembaga pendidikan Syiwa-Buddha yang disebut "asrama" atau "dukuh" yang diformat sesuai ajaran Islam menjadi lembaga pendidikan pondok pesantren. ${ }^{4}$

Tidak dapat diingkari bahwa dalam perjalanan sejarah bangsa Indonesia, pesantren telah memainkan peran transformasi sosial dan kultural di "pejajahan" tanah Nusantara. Pesantren selalu menunjukkan appresiasi terhadap kebudayaan lokal. Pesantren melakukan sikap akomodatif atas kebudayaan kebudayaan dan tradisi-tradisi local di wilayah-wilayah Nusantara tersebut. ${ }^{5}$

Melihat betapa pentingnya aspek pendidikan bagi keberlangsungan hidup manusia, terlebih sebagai internalitas visi dan misi Islam. selanjutnya, umat Islam secara intensif berinovasi membentuk lembaga pendidikan yang disesuaikan dengan perkembangan zaman. Terwujudlah lembaga pendidikan di bawah naungan Muhammadiyah, Persis, al-Irsyad, Hidayatullah dan Nahdlatul Ulama.

Secara khusus, Nahdlatul Ulama memiliki peran yang sangat signifikan dalam proses perkembangan pendidikan, terutama pendidikan Islam. Secara historis pergerakan Nahdlatul Ulama itu sendiri merupakan gerakan pendidikan di seluruh

\footnotetext{
${ }^{2}$ Abudin Nata, Studi Islam Komprehensif, Jakarta : Kencana Prenada Media Group, cet ke-1 2011, hlm. 215

${ }^{3}$ Ngainun Naim, Pengembangan pendidikan Aswaja sebagai strategi deradikalisasi, walisongo, No. 1, Vol.1.2015

${ }^{4}$ Agus Sunyoto, Atlas Wali Songo, Depok : Pustaka Iiman, 2017 hlm. 166

${ }^{5}$ Abi Attabi', Antologi Islam Nusantara dimata habaib, kiyai, santri dan akademisi, Yogyakarta: Aswaja Pressindo, cet ke-1, 2015, hlm. 11
} 
Indonesia. Keberadaan pesantren misalnya, merupakan cikal bakal sistem pendidikan di Indonesia dengan corak dan karakter yang khas dan dianggap telah menjadi ikon masyarakat pribumi dalam memancangkan ideologi pendidikan di Indonesia. ${ }^{6}$

Bagi Nahdlatul Ulama pendidikan menjadi pilar utama yang harus ditegakkan demi mewujudkan masyarakat yang mandiri. Gagasan dan gerakan pendidikan ini telah dimulai sejak perintisan pendirian NU di Indonesia. Dimulai dari gerakan ekonomi kerakyatan melalui Nadlatut Tujjar (1918), disusul dengan Tashwirul Afkar (1922) sebagai gerakan keilmuan dan kebudayaan, hingga Nahdlatul Wathan (1924) yang merupakan gerakan politik di bidang pendidikan, maka ditemukanlah tiga pilar penting bagi Nadhlatul Ulama yang berdiri pada tanggal 31 Januari 1926 M/16 Rajab 1334 H, yaitu: (1) ekonomi kerakyatan; (2) pendidikan; dan (3) kebangsaan.

Untuk merealisasikan pilar-pilar tersebut, Nahdlatul Ulama secara aktif melakukan gerakan sosial-keagamaan untuk memberdayakan umat. Di sini dirasakan pentingnya membuat lini organisasi yang efektif dan mampu merepresentasikan citacita Nahdlatul Ulama. Maka lahirlah lembaga-lembaga dan lajnah; Lembaga Pendidikan (LP) Ma'arif, Lembaga Dakwah, Lembaga Sosial Mabarrot, Lembaga Pengembangan Pertanian, dan lain sebagainya. LP Ma'arif NU dibentuk untuk melakukan gerakan pemberdayaan umat di bidang pendidikan yang sejak semula menjadi perhatian para ulama pendiri (the founding fathers) NU. ${ }^{7}$

\section{Metode}

Penelitian ini menggunakan metode penelitian kualitatif deskriptif, dimana berupaya mendeskripsikan Peranan Lembaga Pendidikan Ma'arif Nahdlatul Ulama dalam penyebaran Pendidikan Islam di Indonesia, dengan hasil pengumpulan data melalui observasi, studi literatur, wawancara, serta dokumentasi, dan dianalisis secara deskriptif. Metode ini merupakan upaya memahami berbagai konsep yang ditemukan dalam proses penulisan. Penelitian yang digunakan pada kondisi obyek yang alamiah, dimana peneliti sebagai instrument kunci, pengambilan sample sumber data dilakukan secara purposive dan snowball, tehnik pengumpulan data dengan triangulasi (gabungan) analisis data bersifat induktif/kualitatif. Sedangkan untuk pengumpulan data peneliti

\footnotetext{
${ }^{6}$ Yusuf Hasyim, "Revitalisasi Lembaga Pendidikan Ma'arif dalam Pengembangan Paradigma Pendidikan Nahdlatul Ulama”, ASNA: Jurnal Kependidikan Islam dan Keagamaan, Vol 1, No 1. 2019

${ }^{7}$ Z.Arifin Junaidi, Ma'arif dalam pusaran sejarah, Jurnal Ma'arif NU, Vol. XV. No 1. 2017
} 
menggunakan beberapa tehnik pengumpulan data penelitian, yaitu observasi, wawancara, dan studi dokumentasi. kemudian data tersebut direduksi, didisplay dan disajikan sesuai dengan prosedur penelitian.

\section{Kajian Litelatur}

Islam adalah agama yang membawa misi agar umatnya menyelenggarakan pendidikan dan pengajaran. Ayat Al-Qur'an yang pertama kali turun adalah berkenaan di samping masalah keimanan juga pendidikan. Allah berfirman pada Qur'an Surat Al'alaq : $1-5$

"Bacalahh dengan (menyebut) nama tuhanmu yang menciptakan, Dia telah menciptakan manusia dan segumpal darah. Bacalah dan tuhanmulah yang paling pemurah. Yang mengajar (manusia) dengan perantaraan kalam. Dia mengajarkan kepada manusia apa yang tidak diketahuinya."

Dan ayat-ayat tersebut di atas dapatlah diambil kesimpulan bahwa seolah-olah Tuhan berkata hendalah manusia meyakini akan adanya tuhan pencipta manusia (dari segumpal darah), selanjutnya untuk memperkokoh keyakinannya dan memeliharanya agar tidak luntur hendaklah melaksanakan pendidikan dan pengajaran.

Bahkan tidak hanya itu Tuhan juga memberikan bahan (materi/pendidikan agar manusia hidup sempurna di dunia ini). Allah SWT berfirman pada Qur'an Surat AlBaqarah: 31 :

"Dan Dia mengajarkan kepada Adam nama-nama (benda-benda) seluruhnya, kemudian mengemukakannya kepada para Malaikat lalu berfirman: "sebutkanlah kepada-Ku nama benda-benda itu jika kamu memang benar orang-orang yang benar!"

Ayat ini menjelaskan bahwa untuk memahai segala sesuatu belum cukup kalau hanya memahami apa, bagaimana serta manfaat benda itu tetapi harus memahami sampai ke hakekat dari benda itu. ${ }^{8}$

Hasan Langgulung merumuskan pendidikan Islam sebagai "proses penyiapan generasi muda untuk mengisi peranan, memindahkan pengetahuan dan nilai-nilai Islam yang diselaraskan dengan fungsi manusia untuk beramal didunia dan memetik hasilnya di akhirat". Disini pendidikan Islam merupakan proses pembentukan individu berdasarkan ajaran Islam yang di wahyukan Allah SWT kepada Nabi Muhammad SAW. Melalui proses mana individu dibentuk agar mencapai derajat yang tinggi

\footnotetext{
${ }^{8}$ Nur Uhbiyati, Dasar-dasar ilmu pendidikan Islam, Semarang: PT. Pustaka Rizki Putra, 2013, cet ke-1, hlm. 47-51
} 
sehingga ia mampu menunaikan tugasnya sebagai khalifah di muka bumi., yang selanjutnya mewujudkan kebahagiaan di dunia dan di akhirat. Tegasnya senada apa yang dikemukakan Ahmad D. Marimba, "pendidikan Islam adalah bimbingan jasmani dan rohani menuju kepada terbentuknya kepribadiaan utama menurut ukuran-ukuran Islam."

LP Ma'arif NU merupakan bagian yang mengurusi bidang pendidikan, pengajaran dan kebudyaan. Selanjutnya Ma'arif yang berstatus bagian dari pada NU mempunyai tugas yang utama dan pertama adalah mencetak kader-kader terdidik yang akan dan mampu mempertahankan ajaran ahlusunnah wal jama'ah, kemudian dalam perkembangannya tugas ini mekar terus sesuai dengan tuntunan zaman.

Lembaga Pendidikan Ma'arif juga sebagai lembaga penanggung jawab pelaksanaan kebijakan pendidikan Nahdlatul Ulama dan berwenang menetapkan tata kerja yang berisi ketentuan-ketentuan umum dan petunjuk operasional yang harus direalisasikan bersama-sama dengan lembaga penyelenggara dan pengelola.

Yang dimaksud lembaga penyelenggara disini adalah lembaga, lajnah, dan badan otonom dilingkungan NU, yayasan, perkumpulan atau lembaga-lembaga lainnya yang membawahi unit-unit atau satuan pendidikan. Sedangkan pengelola adalah pihak pelaksana yang tergabung dalam manajemen unit-unit pedidikan (Seperti TK/RA, MI/SD, MTs/SMP, MA/SMA, PT). ${ }^{10}$

\section{Hasil Dan Pembahasan}

Sejarah membuktikan bahwa peran dan sumbangan NU tidaklah kecil terhadap hajat mencerdaskan kehidupan bangsa. Sumbangan ini tampak lebih besar lagi, betapa lembaga pendidikan NU seperti pesantren, Madrasah atau sekolah NU yang didirikan secara tradisional atas prakarsa dan partisipasi masyarakat melakui semangat Lillahi Ta'ala sekarang dapat berkembang dengan pesat bahkan menjadi pilihan umat. ${ }^{11}$

LP Ma'arif menciptakan konsistensi dan keutuhan langkah-langkah perjuangannya dalam bidang pendidikan adalah ajaran Ahlusunnah wal jamaah sebagai

\footnotetext{
${ }^{9}$ Azyumardi Azra, Pendidikan Islam Tradisi dan Modernisasi di tengah tantangan Milenium III, Jakarta : Kencana, 2012, hlm. 6

${ }^{10}$ PP LP Ma'arif NU, Dinamika Pendidikan Nahdlatul Ulama, PP LP Ma'arif NU, Jakarta, 2009, hal.15

${ }_{11}$ Ali Rahim, Nahdlatul Ulama peranan dan sistem pedidikannya, al-hikmah, Vol. XIV.
} No.2.2013 
dasar filosoinya. Ajaran Ahlusunnah wal Jama'ah ini menjadi wajib bagi tiap-tiap satuan pendidikan LP Ma'arif yang tersebar diseluruh Indonesia. Secara substansial, pembalajaran ini dilakukan dalam kerangka penanaman Ahlusunnah wal Jamaah sebagai doktrin.

Meskipun demikian, dalam potret perjalanannya LP Ma'arif Nahdlatul Ulama tidak hanya terfokus pada misi keagamaan saja, melainkan pada aspek-aspek lainnya yang dibutuhkan masyarakat sesuai dengan perkembangan zaman. Oleh karena itu, Peranan Lemabaga Pendidikan Ma’arif Nahdlatul Ulama di Indonesia meliputi :

\section{Peranan Lembaga Pendidikan Ma'arif Nahdlatul Ulama dalam penyebaran pendidikan di Indonesia}

Program-program kegiatan penyebaran pendidikan Islam yang di intruksikan oleh Pimpinan pusat LP Ma'arif NU Pusat meliputi : Strategi internalisasi Aqidah Ahlusunnah wal Jama'ah, Deradikalisasi di sekolah, Menanamkan cinta tanah air.

a. Strategi internalisasi Aqidah Ahlusunnah wal Jama'ah

Program kegiatan strategi internalisasi Aqidah Ahlusunnah wal Jama'ah yang dilakukan oleh Pengurus Pusat LP Ma'arif NU dengan berbagai cara seperti di adakannya workshop atau seminar pemahaman Ahlusunnah wal Jama'ah, hal ini sekaligus menghimpun permasalahan kemasyarakatan terkait Aqidah Ahlusunnah wal Jama'ah.

Pengurus Pusat LP Ma'arif NU melakukan workshop atau seminar di beberapa pengurus wilayah hingga cabang yang tujuannya untuk menghimpun rumusan dan dijadikan buku induk sekolah maupun untuk siswa dan siswi.

b. Deradikalisasi di sekolah

Terkait deradikalisasi di sekolah, sebenarnya bukan hal yang sulit bagi LP Ma'arif untuk menanganinya, sebab di LP Ma'arif sudah diajarkan Islam moderat sejak dini. dan di ajarkan pentingnya Islam Wasthiyah dalam semua aspek pembelajaran yang ada disekolah.

c. Menanamkan cinta tanah air

Sama halnya deradikalisme disekolah, menanamkan cinta tanah air juga diajarkan sejak dini, bentuk konkret di lingkungan sekolahpun sebagaimana di sekolah 
pada umumnya, yaitu dengan melakukan upacara bendera merah putih setiap senin dan selain itu menyanyikan Lagu Indonesia Raya dan lagu "Syubanul Wathan". 12

\section{Peranan Lembaga Pendidikan Ma'arif Nahdlatul Ulama dalam meningkatkan mutu pendidikan Islam di Indonesia}

Dalam sistem pendidikan, khususnya dunia persekolahan, tuntutan akan pengembangan penjaminan mutu (quality assurance) merupakan gejala yang wajar karena penyelenggaraan pendidikan merupakan bagian dari public accountability. Setiap komponen stakeholders pendidikan, baik orang tua, masyarakat, dunia kerja, maupun pemerintah dalam peranan dan kapasitasnya masing-masing memiliki kepentingan terhadap penyelenggaraan pendidikan yang bermutu.

Karenanya, peningkatan mutu pendidikan terus dilaksanakan oleh LP Ma'arif NU. Misalnya pada tahun 2004 silam LP Ma'arif mengadakan forum silaturahim pendidikan dengan tajuk, "menyambut Tahun Mutu Pendidikan 2005". Forum yang banyak dihadiri banyak komponen ini, yaitu diantaranya oleh pengurus PBNU, pengurus PP LP Ma'arif NU, unsur depdiknas, unsur depag, dan lainnya. Membincang banyak hal menyangkut kondisi obyektif dunia pendidikan, utamanya pendidikan yang berada dilingkungan NU. ${ }^{13}$

Untuk selanjutnya, peningkatan mutu pendidikan ini terus dilakukan oleh pengurus pusat, baik dalam pengembangan Sumber Daya Manusia, sistem pendidikan maupun sarana dan prasarananya.

a. Pengembangan Sumber Daya Manusia

Proses sumber daya manusia bukanlah proses yang terisolasi dengan fungsifungsi menejemen sumber daya manusia lain juga membutuhkan program pengembangan sumber daya manusia untuk peningkatan evektifitasnya. Untuk itu, sangat penting upaya pengembangan SDM bagi terwujudnya SDM bidang pendidikan yang berkualitas. Pengembangan SDM dilakukan melalui pendidikan dan pelatihan,

\footnotetext{
${ }^{12}$ Syubanul wathan adalah lagu yang di gubah oleh KH. Wahab hasbullah, lagu ini di ciptakan atas kepedulian tanah air indonesia yang kala itu mengalami penjajahan

${ }^{13}$ Wajah pendidikan NU: pergumulan mempertegas identitas, Jurnal Ma'arif, Edisi IX Januari 2005, hlm. 4-5
} 
baik secara formal maupun informal, yang dilaksanakan secara simultan berkelanjutan. $^{14}$

b. Pengembangan Sistem Pendidikan

Selanjutnya dalam upaya meningkatkan mutu pendidikan adalah pengembangan sistem pendidikan yakni mentransformasikan sistem pendidikan yang sesuai dengan perkembangan zaman, dalam pembaharuan ini tentu manfaat praktisnya mampu memberi atensi kepada masyarakat dan outputnya menjadikan lulusan sekolah menjadi pribadi yang siap untuk menghadapi tantangan zaman.

\section{Peranan LP Ma'arif NU dalam merespon pengaruh globalisasi}

Dalam merespon perubahan globalisasi setidaknya ada 5 hal yang disediakan untuk sumber daya manusia agar mampu bertahan dan akan terus bisa meneruskan hidup. Pertama adalah manusia yang memiliki skill/keterampilan atau justru ekport keahlian tertentu yang akan survive, kedua adalah penguasaan bahasa bisa menjadi tolok ukur value seseorang, ketiga adalah penguasaan ICT (Information Comunication Technologi), keempat nettworking dan kelima adalah karakter. Dari kelima hal ini akan coba dikembangkan disatuan pendidikan LP Ma'arif NU

a. Mengembangkan skill/keterampilan

LP Ma'arif terus berusaha menciptakan lulusan yang tidak hanya mahir dalam bidang keagamaan akan tetapi mampu mencetak Sumber Daya Manusia yang professional, sehingga tidak mengherankan di beberapa satuan pendidkan LP Ma'arif bekerjasama dengan perusahaan-perusahan benefit yang nantinya akan menjadi tempat peraktikum langsung siswa-siswi LP Ma'arif khususnya Sekolah Kejuruan Ma'arif NU.

b. Penguasaan Bahasa

Selain untuk memperbaiki komunikasi global, penguasaan bahasa juga mampu mencegah seseorang terjadinya sesuatu hal yang tidak di inginkan. Dan begitupun upaya yang terus dilakukan oleh satuan LP Ma'arif adalah penguasaan bahasa asing guna mempermudah kerjasama dengan pihak luar negeri ataupun sebagai pemenuh kebutuhan Sumber Daya Manusia yang berdaya saing.

${ }^{14}$ Abdul Madjid Latief, Evaluasi Kinerja Sumber Daya Manusia, Ciputat : Haja Mandiri, Cet ke-1 2019, hlm. 179 


\section{c. Penguasaan Informasi Komunikasi dan Teknologi}

Upaya yang dilakukan satuan pendidikan LP Ma'arif adalah bekerjasama dengan pihak lain yang kaitannya dengan Informasi dan Teknologi. Menjadi sangat penting dizaman globalisasi saat ini dalam penguasaan Teknologi, sebab hampir semua elemen kebutuhan hidup telah bertranspormasi keteknologi yang tidak lain adalah untuk mempermudah dalam segala keperluannya.

d. Memperbanyak jaringan kerja

Kemudian upaya yang dilakukan satuan LP Ma'arif dalam menghadapi era globalisasi yakni memperbanyak jaringan kerja dengan pihak lain, guna mencetak lulusan yang berkopeten sesuai bidangnya, sekaligus sebagai investasi pengetahuan dari pihak lain yang nantinya dikembangkan diwilayahnya masing-masing. Kemudian upaya yang dilakukan satuan LP Ma'arif dalam menghadapi era globalisasi yakni memperbanyak jaringan kerja dengan pihak lain, guna mencetak lulusan yang berkopeten sesuai bidangnya, sekaligus sebagai investasi pengetahuan dari pihak lain yang nantinya dikembangkan diwilayahnya masing-masing.

e. Membentuk karakter

Dalam hal membentuk karakter, tentu tidak hanya mengemban dalam konsep intelektual semata, akan tetapi menjadikan konsep spiritual dan akhlak sebagai menifestasi yang utama. Sehingga dalam point terakhir ini, yang kaitannya dengan modal dasar untuk menghadapi era globalisasi, LP Ma'arif memiliki modal unggulan yakni pembentukan karakter Islami dalam arti luas yang saat ini mungkin sudah mulai pudar dilembaga-lembaga pendidikan lainnya.

\section{Simpulan}

Berdasarkan hasil penelitian dan pembahasan serta mengacu pada rumusan masalah yang diajukkan pada penelitian yang berjudul Peranan Lembaga Pendidikan Ma'arif Nahdlatul Ulama dalam Penyebaran Pendidikan Islam di Indonesia, dapat diambil kesimpulan sebagai berikut :

Pertama, LP Ma'arif Merupakan refresentasi dari Jami’yah Nahdlatul Ulama yang dalam potret sejarahnya merupakan organisasi yang lahir dari rahim intelektual Islam Tradisional yang beraqidah Ahlusunnah wal jama'ah. Selanutnya LP Ma'arif 
menciptakan konsistensi dan keutuhan langkah-langkah perjuangannya dalam bidang pendidikan adalah ajaran Ahlusunnah wal jamaah sebagai dasar filosoinya

Kedua, peran yang dilakukan LP Ma'arif dalam meningkatkan mutu pendidikan LP Ma'arif meliputi pembenahan input, proses dan output serta mengoptimalkan segala sumber daya yang ada secara berkesinambungan. Misalnya dalam sumber daya manusia dilakukannya peningkatan profesionalisme tenaga pendidik dan kependidikan serta pelayanan proses pembelajaran pada siswa. Sumber daya lainnya pembenahan sarana dan prasarana pendidikan, pembenahan sumber daya kurikulum dan penerapan budaya mutu.

Ketiga, Peran LP Ma'arif dalam merespon pengaruh globalisasi dengan memberikan pembekalan kepada siswa pada tiap-tiap satuan pendidikan LP ma'arif dengan cara : Memberikan rangsangan skill/keterampilan, penguasaan bahasa, penguasaan ICT (Information, Communication, Technologi), nettworking dan pengembangan karakter.

\section{Daftar Pustaka}

Attabi', Abi, Antologi Islam Nusantara dimata habaib, kiyai, santri dan akademisi, Yogyakarta: Aswaja Pressindo, 2015.

Azra, Azyumardi, Pendidikan Islam Tradisi dan Modernisasi di tengah tantangan Milenium III, Jakarta : Kencana, 2012.

Hasyim, Yusuf, 2019, Revitalisasi Lembaga Pendidikan Ma'arif dalam Pengembangan Paradigma Pendidikan Nahdlatul Ulama, ASNA: Jurnal Kependidikan Islam dan Keagamaan, Vol 1, No 1.

Junaidi, Z.Arifin, 2017, Ma'arif dalam pusaran sejarah, Jurnal Ma'arif NU, Vol. XV. No 1.

Latief, Abdul Madjid, Evaluasi Kinerja Sumber Daya Manusia, Ciputat : Haja Mandiri, 2019.

Naim, Ngainun, 2015, Pengembangan pendidikan Aswaja sebagai strategi deradikalisasi, walisongo, No. 1, Vol.1.

Nata, Abuddin, Studi Islam Komprehensif, Jakarta : Kencana Prenada Media Group, 2011.

PP LP Ma'arif NU, 2009, Dinamika Pendidikan Nahdlatul Ulama, PP LP Ma'arif NU, Jakarta.

Rahim, Ali, 2013,Nahdlatul Ulama, peranan dan sistem pendidikannya”, Jurnal AlHikmah, Vol. XIV. No 2.

Rohani HM, Ahmad, 2009, Pendidikan Islam, menuju generasi khairu ummah, Portal Garuda, Vol 47, No 118. 
Fikrah: Journal of Islamic Education, Vol. 4 No. 1 Juni 2020

Sunyoto, Agus, Atlas Wali Songo, Depok : Pustaka liman, 2017.

Tim Redaktur, "Wajah pendidikan NU: pergumulan mempertegas identitas", Jurnal Ma'arif, Edisi IX Januari 2005.

Uhbiyati, Nur, Dasar-dasar ilmu pendidikan Islam, Semarang: PT. Pustaka Rizki Putra, 2013. 